\title{
Enhancement of fixed-ratio performance by briefly presented conditioned reinforcing stimuli'
}

\author{
JOHN R. THOMAS AND ALAN STUBBS \\ INSTITUTE FOR BEHAVIORAL RESEARCH, SILVER SPRING, MARYLAND
}

Rates of responding increased above tandem control rates and characteristic fixed-ratio patterns of responding developed within each fixed-ratio component of a larger fixedratio requirement when the completion of each component produced a brief presentation of a stimulus associated with primary reinforcement.

Stimuli which are intermittently associated with the presentation of primary reinforcement are capable of enhancing the frequency and pattern of responding in extended sequencies of behavior when such stimuli are presented following the completion of each component in the behavioral sequence (Findley \& Brady, 1965; Kelleher, 1966). The present study investigated the effects on fixed-ratio performances of pigeons of briefly presented stimuli intermittently associated with primary reinforcement.

Method

The Ss were two adult, male, white Carneauxpigeons (T7 and T9) maintained at approximately $80 \%$ of their free-feeding body weights. The experimental space was a standard single key pigeon chamber. Programming and recording was accomplished automatically by a system of switching relays and timers.

The Ss first performed on a multiple fixed-ratio fixed-ratio schedule of reinforcement. In the presence of a red key light, a fixed-ratio (FR) 150 requirement was in effect. In the presence of a white key light, an identical FR 150 was in effect. The two FR schedules alternated unsystematically and the schedule alternation occurred after reinforcement. A reinforcement consisted of a 4-sec. presentation of the food tray. The house light and key light were unilluminated and the food was illuminated by the feeder light during the 4-sec. reinforcement presentation. An experimental session lasted for 50 reinforcements and each of the two FR schedules appeared for approximately half of the session. The Ss performed on the multiple FR FR schedule for 32 sessions.

Following the above sessions, the program was changed such that in the red key light FR every 30th response in the completion of the FR 150 requirement produced a $0.5-\mathrm{sec}$. illumination of the feeder light. The house light and key light remained illuminated during the $0.5-\mathrm{sec}$. feeder light presentation. The schedule in the presence of the red key light may be viewed as a chain FR 30 FR 30 FR 30 FR 30 FR 30 (Ferster \& Skinner, 1957), or as a second order schedule, FR 5 (FR 30) (Kelleher, 1966), in which five FR 30 requirements must be completed in order to produce primary reinforcement. Rate of responding in the red key light FR was recorded separately for each of the five FR 30 components. The FR 150 requirement was still programmed as before in the presence of the white key light without the occurrence of any exteroceptive stimulus changes during the completion of the FR requirement. Rate of responding in the white key light FR, however, was also recorded separately for the five successive blocks of 30 responses in the FR 150 . The white key light FR schedule essentially served as a tandem control condition for the effects of the brief feeder light presentations in the red key light FR schedule. The Ss performed on the above procedure for 62 sessions.

\section{Resulis and Discussion}

The overall response rate (based on the mean of the last four sessions) of $T 7$ for the FR schedule in the presence of the red key light was 106.8 responses per minute and the response rate for the FR schedule in the presence of the white key light was 112.0 responses per minute. When the 0.5-sec. illumination of the feeder light followed every 30 th response in the completion of the FR 150, the overall response rate of $T 7$ in the presence of the red key light increased to 140.3 responses per minute and the response rate for the FR schedule in the presence of the white key light was 119.0 responses per minute. The FR response rate of $\mathrm{T} 9$ in the red key light $\mathrm{FR}$ schedule was 56.7 responses per minute and the response rate in the white key light FR schedule was 57.2 responses per minute. When the 0.5-sec. illumination of the feeder light followed every 30 th response in the completion of the FR 150, the response rate of $\mathrm{T} 9$ in the red key light FR was 70.4 responses per minute and the FR response rate in the white key light FR was 58.7 responses per minute.

Figure 1A is a cumulative record of $T 7$ from a portion of a session on the multiple FR FR schedule. The pips of the recording pen indicate the completion of every 30 th response and the recording pen resets to baseline each time the FR 150 requirement is completed and food reinforcement occurs. Excursions of the recording pen during which the bottom event pen is up indicate FRs in the presence of the red key light; excursions during which the bottom pen is down indicate FRs in the presence of the white key light. Figure $1 \mathrm{~B}$ is a segment of a cumulative record of $T 7$ from a session on the multiple schedule when the $0.5-\mathrm{sec}$. feeder light illumination followed the completion of every 30th response in the presence of the red key light. In Fig. 1B, it may be seen that there was a decrease in the pre-ratio 

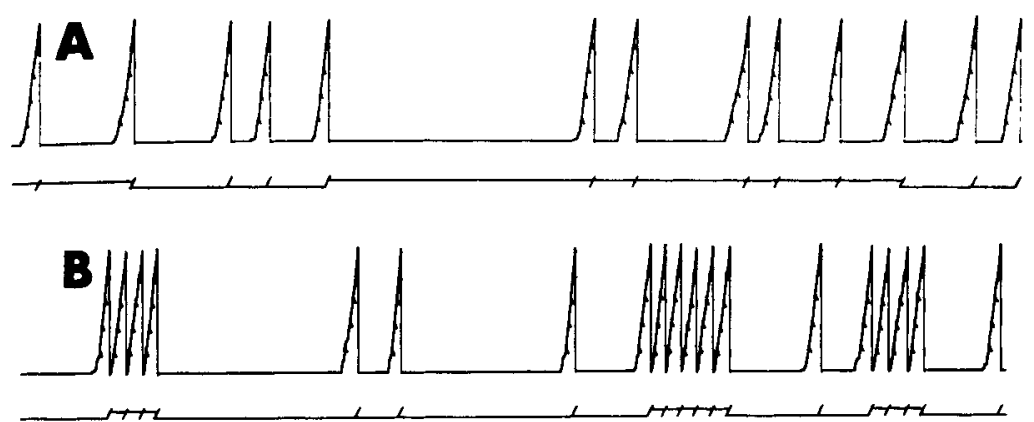

Fig. 1. Cumulative response records of T7 on (A) the multiple FR 150 FR 150 schedule and on $(B)$ the same multischedule when the brief feeder light presentations follow every 30 th response in the red key light $F R$.

pause and an increase in the response rate in the presence of the red key light. There may also be seen the development of small pre-ratio pauses following each presentation of the $0.5-\mathrm{sec}$. feeder light illumination.

In Fig. 2A are shown the response rates of $\mathrm{T} 7$ for each of the five FR 30 components for the red key light FR (dashed line) and the white key light FR (solid line) of the multiple FR FR schedule. Figure 2B presents the response rates of $T 7$ for each of the five FR 30

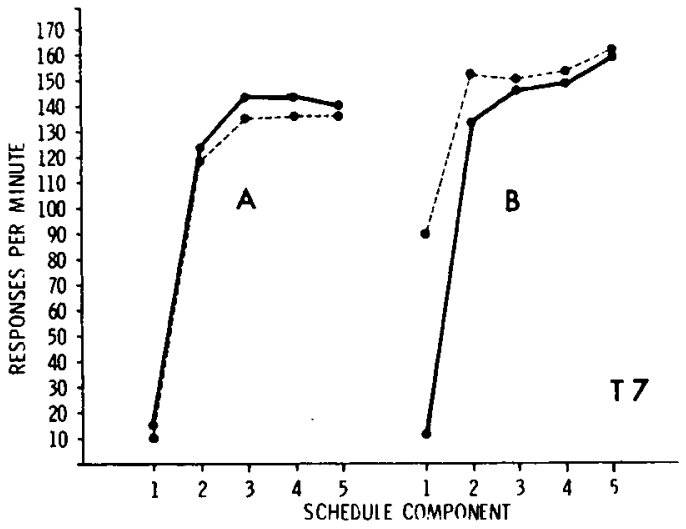

Fig. 2. Response rates of $T 7$ in each of the five $F R 30$ components of the red key light FR (dashed lines) and the white key light FR (solid lines) on (A) the multiple FR 150 FR 150 schedule and on (B) the same multiple schedule when the brief feeder light presentations follow each FR 30 component in the red key light FR. components for the two key light conditions when each of the FR 30 components in the presence of the red key light was followed by the $0.5-\mathrm{sec}$. feeder light illumination. Figure $2 B$ shows that the largest increase in response rate with the brief feeder light presentations occurred in the first and second FR 30 components, although response rates increased in the last three FR 30 components of the red light condition also. The performance of $\mathrm{T} 9$ generally replicated the changes in response rates in the separate $\mathrm{FR} 30$ components that occurred for $\mathrm{T} 7$ with the introduction of the brief feeder light presentations.

The increase in response rates as well as the development of characteristic FR patterns of responding within each FR 30 component when the feeder light was presented following every 30 th response of the red key light condition of the multiple schedule indicates that the brief feeder light presentations functioned as effective conditioned reinforcing stimuli over extended periods of time.

\section{References}

Findley, J. D., \& Brady, J. V. Facilitation of large ratio performance by use of conditioned reinforcement. J. exp. Anal. Behav., $1965,8,125-129$.

Kelleher, R. T. Chaining and conditioned reinforcement. In W. K. Honig (Ed.), Operant behavior: areas of research and application. New York: Appleton-Century-Crofts, 1966.

\section{Note}

1. The research was supported by grant NsG-450, National Aeronautics and Space Administration. 